Journal of

Dentistry and Oral Health

\title{
Cross-Sectional Data Analysis of the Outcome after Root Tip Resection with or without Previous Root Canal Revision or Retrograde Root Filling
}

\section{Mayte Buchbender ${ }^{1,}$, Thomas Sottong ${ }^{1}$, Marco-Rainer Kesting ${ }^{2}$, Christian-Martin Schmitt ${ }^{1}$}

${ }^{1}$ Department of Oral and Maxillofacial Surgery, University of Erlangen- Nuremberg, Erlangen, Germany

${ }^{2}$ Professor and Chair of Oral and Maxillofacial Surgery, University of Erlangen- Nuremberg, Erlangen, Germany

${ }^{\star}$ Corresponding author: Dr. Mayte Buchbender, Department of Oral and Maxillofacial Surgery, University of ErlangenNuremberg, Glückstrasse 11, 91054 Erlangen, Germany, Tel: +49 91318533614 Fax: +49 9131 8533657; E-mail:mayte.buchbender@uk-erlangen.de

Received Date: September 08, 2019 Accepted Date: October 12, 2019 Published Date: October 15, 2019

Citation: Mayte Buchbender (2019) Cross-Sectional Data Analysis of the Outcome after Root Tip Resection with or without Previous Root Canal Revision or Retrograde Root Filling. J Dent Oral Health 6: 1-8.

\begin{abstract}
Purpose: This study aimed to analyze the influence of preoperative root canal revision on the outcome of subsequent root tip resection. Moreover, we investigated the impact of retrograde filling or no retrograde filling in terms of root tip resection.

Methods: Patients with a need of retreatment after initial root canal filling with periapical infection between 2011 and 2017 were enrolled, and 4 groups were formed. Group 1 had a revision before root tip resection, and Group 2 had primary root tip resection (1a/2a with retrograde filling, 1b/2b without retrograde filling). Clinical (tooth still in situ) and radiographic parameters (improved periapical index preoperative 3 or 4 to postoperative 1 or 2) were analyzed.

Results: Forty-eight teeth (Group $1 \mathrm{a} n=14,2 \mathrm{a} n=15 ; 1 \mathrm{~b} n=8,2 \mathrm{~b} n=11$ ) underwent a root tip resection ( $\mathrm{n}=17$ front teeth, $\mathrm{n}=16$ premolars, $\mathrm{n}=25$ molars) with a mean follow-up interval of 14.8 months. The total clinical success rate was $75.9 \%$. Radiographic success rates were as follows: group $1 \mathrm{a}(64.3 \%), 1 \mathrm{~b}(62.5 \%), 2 \mathrm{a}(33.3 \%)$, and $2 \mathrm{~b}(18.8 \%)$.

Conclusion: Within the limits of the cross-sectional study design, preoperative root canal revision and retrograde root canal filling should be considered to maximize the long-term success rate of teeth.
\end{abstract}

C2019 The Authors. Published by the JScholar under the terms of the Creative Commons Attribution License http://creativecommons.org/licenses/ by $/ 3.0 /$, which permits unrestricted use, provided the original author and source are credited. 


\section{Introduction}

Irreversible pulpitides or infected pulpanecroses are the most common indication for endodontic treatment in conservative dentistry. The initial success rate after root canal treatment remains high due to further development of techniques and instruments. Nevertheless, apical inflammations recur in many cases, which is mostly caused by the persistence of microorganisms or their ramifications, especially in the apical third of the root [1]. In this region, the bacteria cannot always be eliminated in a predictable way, despite chemomechanical preparation [1]. Studies have shown up to $64 \%$ persistence of pathogens after root canal treatment, which could only be minimized to $36 \%$ after drug insertion with calcium hydroxide [2]. The existing inflammatory stimulus due to persistent microorganisms is followed by a cytokine-mediated immunological reaction, bone resorption and finally apical periodontitis [3].

If the initial root canal treatment fails, the first step should be to revise the root canal in order to ensure tooth preservation $[4,5]$. The goal of a revision remains unchanged, which is to completely disinfect the entire root canal system to prevent reinfections [6,7]. If this treatment also remains a failure and apical inflammation persists, surgical intervention is indicated. Through surgical access via the vestibular bone lamella, the root apex in the last apical third of the root and the granulation tissue are removed. This method also focuses on tooth preservation. After removal of the root tip, retrograde preparation and root canal filling can achieve a bacteria-proof filling and prevent a new inflammatory stimulus [8]. The choice of the appropriate therapy procedure varies between endodontists and surgeons, and the current data situation can shed light on this controversy.

In a review, Torabinejad et al. investigated the clinical success of a surgical intervention and two conservative endodontic treatments. While the surgical success rate was $77.8 \%$ over a follow-up of 2-4 years, it was $70.9 \%$ for the repeated conservative approach. Over a monitoring period of 4-6 years, the success rate for surgery was $71.8 \%$, while the success rate for revisions was $83.0 \%$. Success was measured by the absence of clinical symptoms and changes in apical radiotranslucence [9]. The authors concluded a higher long-term success rate for revisions $[3,10]$. Other studies, however, saw no significant difference in long-term success (follow-up $>4$ years) between the two therapy approaches [12]. The study criteria are usually very heterogeneous, and there is often a lack of data, especially on the retrograde occlusion. However, this can be significantly associated with higher success rates [13].
Overall, there is currently no clinical evidence to give preference to one therapeutic approach over another. The indicationfor primary root tip resection might be set too quickly, and the attempt of a previous revision is waived. In the case of a root tip resection, the question of whether to perform retrograde filling also arises.

This study was intended to examine the outcomes after root tip resection with or without a previously performed revision. In addition, the outcome should be analyzed with respect to retrograde preparation and filling or only resection as well as the evaluation of different filling materials.

\section{Materials and Methods}

\section{Study design and setup}

The data was analyzed in a cross-sectional study design. Patients with a need of retreatment after initial root canal filling and a periapical infection (persistent periapical dolence or painful percussion and apical translucency) between 2011 and 2017 were enrolled. Ethical approval (No. 39_18Bc) was obtained from the ethics committee of the University of Erlangen-Nuremberg.

Regarding the inclusion criteria, we defined the presence of pre- and postoperative X-rays as well as the documentation of clinical parameters. We have also defined at least one follow-up visit at least 6 weeks after surgical intervention as an inclusion criterion.

Patients who could no longer be reached or had their aftercare performed by their general dentist and did not want to introduce themselves again were excluded. Moreover, patients with comorbidity factors (diabetes mellitus, immunological diseases, radiation therapy, antiresorptive therapy), smokers or mentally and physically impaired patients, and minors were excluded.

According to the therapy carried out, four groups were retrospectively formed. The first group (1) received a revision of the root canal treatment before root tip resection and either received a retrograde filling (1a) or did not (1b). The second group (2) did not receive a revision before resection and either received a retrograde filling (2a) or did not (2b).

The preoperative assessment of the existing root canal treatment (initial or after revision) was standardized on the basis of the available $\mathrm{x}$-rays according to the following parameters:

1. Root filling in apical third $2 \mathrm{~mm}$ before apex

2. marginal and bubble-free root canal filling

3. without apical puff of the filling 
Only patients who met the criteria were included. All patients were then pseudonymised according to the above criteria.

\section{Data extraction (parameters/examination)}

Two researchers (one dentist, one oral surgeon) analysed the patients according to the following parameters. Clinical parameters:

1. Vitality, percussion

2. Periapical dolence

3. Tooth loosening

4. Pocket depth

\section{Radiographic parameter PAI Index}

The PAI = periapical index by Orstavik et al. [14], including the following categories: grade 1 (no signs of the apical tissue), grade 2 (minor changes of bone structure), grade 3 (changes of bone structure with loss of mineral), grade 4 (periodontitis with radiotranslucency), and grade 5 (severe apical periodontitis with signs of exacerbation). A postoperative PAI of 1 or 2 was defined as treatment success [15].

\section{Root canal revision}

The revisions were performed by dentists at the University Hospital. The tooth was isolated with the help of a latex-free rubberdam (Roeko Dental Dam, Langenau, Germany). The revision of the former root canal filling was done mechanically with the reciproc system (VDW, München, Germany). After removing the filling and disinfecting the root canal system with irrigants (Sodium hypochlorite 3\% and citric acid 40\%), the length of the root canals was measured with the help of Raypex (VDW München, Germany) before refill. After drying the canals, confected gutta-percha and root canal sealer (AH plus DentsplyDeTrey ,Konstanz, Germany) were inserted in each canal. The cavity was sealed with a condensable composite (Clearfill majesty Kuraray ,Hattersheim, Germany) after selective etch of dentin and enamel with phosphoric acid (40\%) and dentin bonding (SyntacIvoclarVivadent, Schaan, Liechtenstein).

\section{Surgical root tip resection}

Surgical interventions were performed by different surgeons to reduce the bias. After the formation of a mucoperiosteal flap, the access cavity through the buccal bone to the root tip was prepared with rotating instruments (W\&H Dentalwerk, Bürmoos, Austria) and with using a loop glasses. After identification of the causative root tip, it was rotatably separated, and the inflammation was curetted around the cavity. In the case of a subsequent retrograde preparation of the root and a sufficient root filling, this procedure was done using the piezo ultrasound (Mectron, Cologne, Germany). The retrograde closure was carried out either with Super-EBA (zinc oxide eugenol with addition of ethoxybenzoic acid) cement (3M ESPE, Neuss, Germany) or MTA (mineral trioxide aggregate, ProRoot Dentsply Sirona, Bensheim, Germany). The wound closure was performed with absorbable sutures Vicryl (Johnson \& Johnson, Norderstedt, Germany).

\section{Outcomes}

Our primary outcomes were defined as clinical success using the mean number of tooth loss in the different treatment approaches in the four groups. As secondary outcomes, we defined the radiographic outcome using the mean improvement of PAI.

\section{Statistical analysis}

Two-sided adjusted $p$-values $\leq 0.05$ were considered to be significant. The analyses were performed using the Software R (Version 3.6.0) on Linux Kemel (Version 4.4.0-148). The association of the different treatment approach variable with clinical and radiographic outcome was analysed non- paramteric Wilcoxon-test and chi-square for categorical variables.

\section{Results}

\section{Patient Cohort}

Of the analysed patients, $n=48$ teeth with 58 pathologic roots were included. As illustrated in Table 1, we assigned the patients to 4 groups according to the therapy procedure carried out (with/without revision before resection and with/without retrograde filling) (1a, 1b, 2a, 2b). We included 17 front teeth, 16 premolars and 25 roots of molars. The mean follow-up was 14.8 months. The parameter pocket depth was omitted due to lack of continuous documentation.

\section{Clinical Outcome}

Of the root tip resections that we considered, 14 teeth clinically failed across all patient groups because they had to be extracted during follow-up, which resulted in a total success rate of $75.9 \%$ with the mean follow-up of 14.8 months. In patient group 1a, a success rate of $85.7 \%$ was calculated for the patients who received a root canal revision before the operation and a retrograde root filling. In patient group $1 \mathrm{~b}$, a success rate of $77.7 \%$ was observed. 
Table 1. Showing the patient cohort and related outcomes

\begin{tabular}{|l|l|l|l|l|l|l|}
\hline Group & Teeth/roots & Front teeth & Premolars & Molars & Clinical success rate & Radiological success rate \\
\hline $1 \mathrm{a}$ & $\mathrm{n}=14 / \mathrm{n}=14$ & $\mathrm{n}=6$ & $\mathrm{n}=7$ & $\mathrm{n}=1$ & $85.7 \%$ & $64.3 \%$ \\
\hline $1 \mathrm{~b}$ & $\mathrm{n}=8 / \mathrm{n}=9$ & $\mathrm{n}=3$ & $\mathrm{n}=2$ & $\mathrm{n}=4$ & $77.7 \%$ & $62.5 \%$ \\
\hline $2 \mathrm{a}$ & $\mathrm{n}=15 / \mathrm{n}=19$ & $\mathrm{n}=4$ & $\mathrm{n}=6$ & $\mathrm{n}=9$ & $78.9 \%$ & $33.3 \%$ \\
\hline $2 \mathrm{~b}$ & $\mathrm{n}=11 / \mathrm{n}=16$ & $\mathrm{n}=4$ & $\mathrm{n}=1$ & $\mathrm{n}=11$ & $62.5 \%$ & $18.8 \%$ \\
\hline total & $\mathrm{n}=48 / \mathrm{n}=58$ & $\mathrm{n}=17$ & $\mathrm{n}=16$ & $\mathrm{n}=25$ & $75.9 \%$ & $42.0 \%$ \\
\hline
\end{tabular}

Patients who did not receive a root canal revision but received a retrograde root canal filling were in group $2 a$, in which we observed a clinical success rate of $78.9 \%$.

In patient group $2 \mathrm{~b}$, with neither a root canal revision nor a retrograde root filling, clinical success was observed in only $62.5 \%$ of the cases. These observations are without statistical significance and are illustrated in (Figure 1).

Figure 1: Presentation of the clinical survival rates depending on the chosen treatment concept within the patient groups.

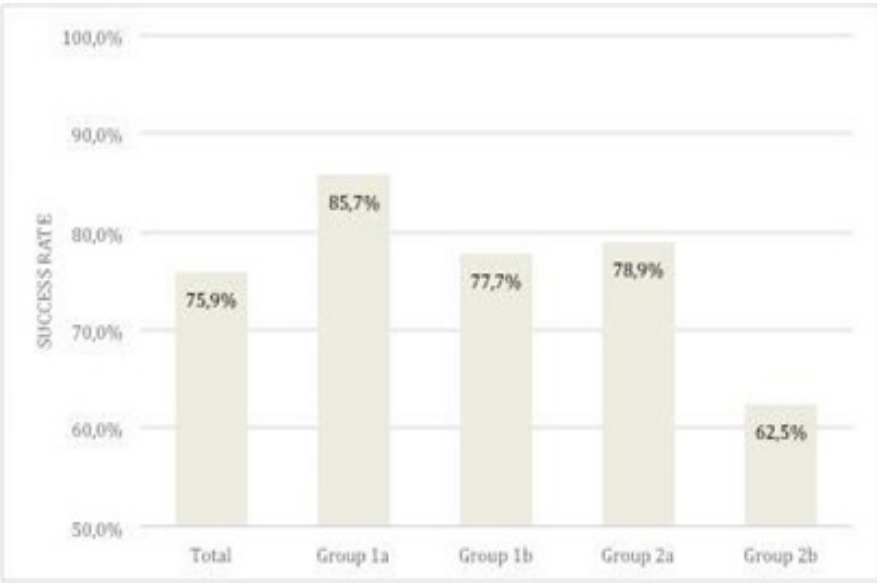

Regardless of the treatment procedure and the jaw, anterior teeth performed significantly better with $88.2 \%$ clinical success rate compared to premolars, which had only $50.0 \%$ clinical success rate $(\mathrm{p}=0.02)$. The success rate for molars was $84.0 \%$. This result was statistically significant $(\mathrm{p}=0.03)$, as seen in (Figure 2).

We also observed the clinical outcome depending on the retrograde filling material in groups 1a and 2a. Two root filling materials were used for the selected patient cases: MTA and Super-EBA. The success rate was $50.0 \%$ for MTA and $88.8 \%$ for Super-EBA ( $\mathrm{p}=0.05)$, as seen in (Figure 3 ).
Figure 2: Clinical success rate of all included roots depending on the tooth position. Mean follow-up intervals $=17.5$ months for anterior teeth, 14.2 months for premolars and 13.5 months for molars.

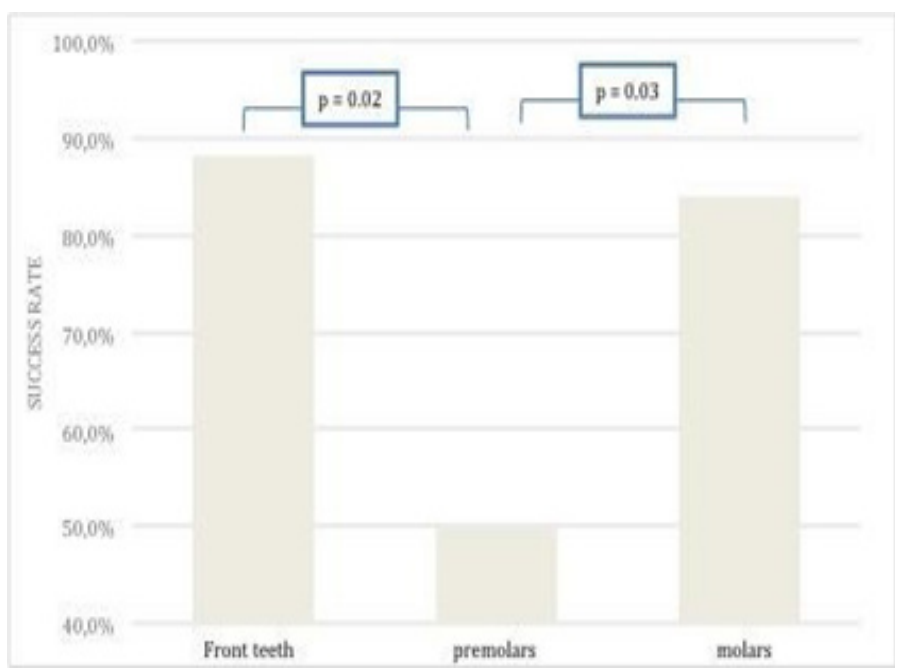

Figure 3: Clinical success rate of root tip resection depending on the material used for retrograde root filling.

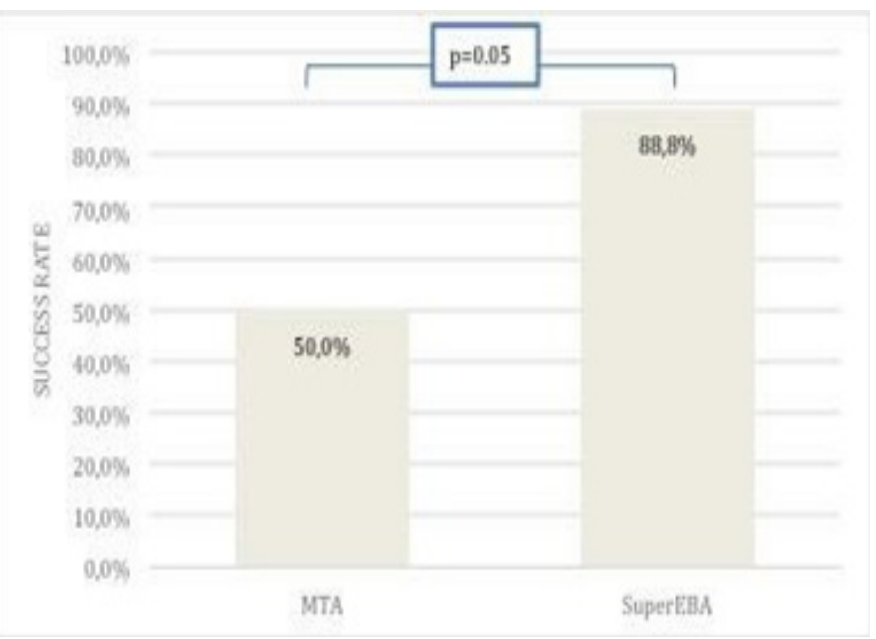




\section{Radiographic Outcome}

All roots with a preoperative PAI of 3, 4 or 5 (50 roots in total) were selected for evaluation within the patient population. Roots with a preoperative PAI of 1 or 2 were not included in the evaluation ( 8 roots in total) to reach better comparability. Treatment success was observed when the included roots had dropped to PAI 1 or 2 .

In the first group (1a), $64.3 \%$ of all roots with a preoperative PAI $>2$ were treated successfully. The success rate was $62.5 \%$ in the second group (1b), 33.3\% in the third group (2a), and only $18.8 \%$ in the fourth group (2b), which did not receive either a root canal revision or a retrograde root filling. These findings were not significant and are illustrated in (Figure 4).

Figure 4: Radiological outcome of the treatment success within the patient groups taking into account the radiographic PAI evaluation.

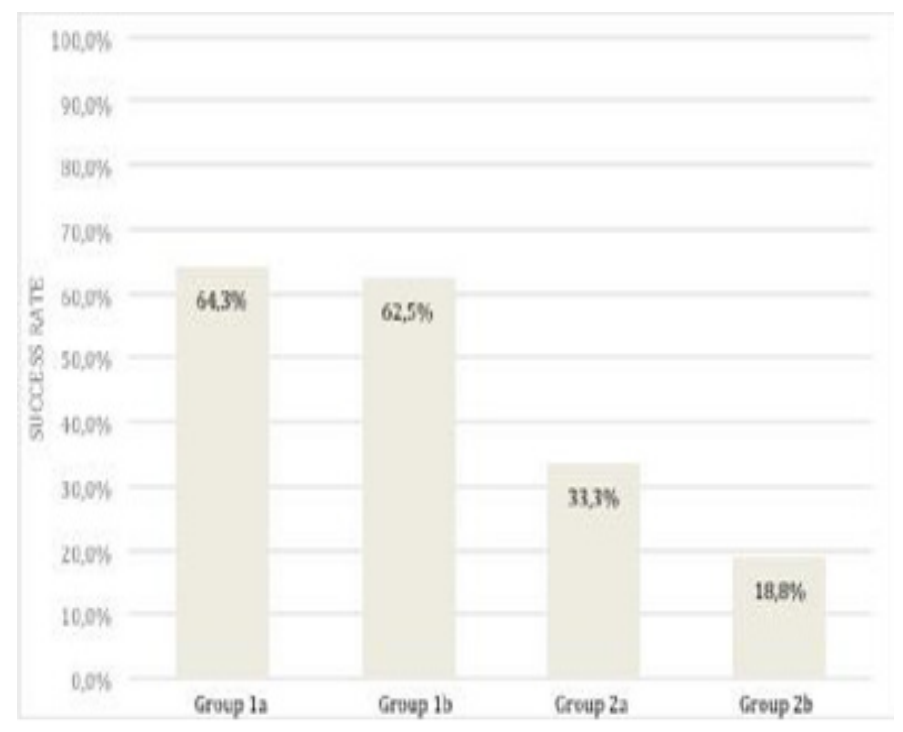

\section{Discussion}

The therapy approaches for persistent apical inflammations are manifold. The decision between conventional revision before surgical intervention and surgical procedure clearly depends on the qualifications of the practitioner, the equipment, and the size of apical inflammation. A surgical approach is usually prematurely indicated due to the rapid growth of implant dentistry. To the best of our knowledge, there is currently no evidence in the literature and no medical guideline can be derived for or against one therapy concept over another. For this reason, this cross-sectional study was designed. The aim of this study is to determine the success rates of two different approaches: root tip resection after revision or immediate root tip resection. There have already been investigations in the literature as to whether the root canal should undergo retrograde filling in the case of a resection.
Looking at the current literature, the success rates of different approaches vary greatly. Friedman et al. performed a review in 2011, in which he included 7 studies demonstrating the success rate to be between $37 \%$ and $91 \%$. Nonetheless, this is a large interval, and the studies are difficult to compare [16]. The follow-up intervals are not uniform as is the definition of treatment success [17]. To obtain meaningful results over a defined period of time, at least $80 \%$ of the included patients must appear at the scheduled recall appointment [18].Therefore, patients in our patient population who did not appear for check-up were re-examined due to the cross-sectional design. We recorded a mean follow-up of 14.8 months. This follow-up period is notably short compared to the documented data in the literature $[9,11,12]$. Due to the study design, however, no longer observation period could be determined. Clinical and radiological parameters are used to assess the success of the treatment and are separated from each other $[19,20]$. The reason for the separation is that in many cases, patients do not describe clinical symptoms despite radiological correlates [27]. In addition, the clinical symptoms, such as periapical pressure, dolence or pain, are also subjective, which is why tooth loss was used to determine the clinical failure and respective success. For radiological diagnosis and evaluation of healing, two- dimensional X-ray diagnosis in the form of panoramic tomography or single-tooth films are sufficient according to the literature. However, the magnification angles on panoramic images or eccentrically X-rayed images make uniform evaluation somewhat difficult, as well. For a better assessment of the root tips or root canal treatments, three-dimensional diagnostics, e.g. conebeam computed tomography (CBCT), can be considered [21]. In this study, we analyzed panoramic X-rays or tooth films and evaluated the PAI Index.

The clinical treatment success was defined by whether the resected tooth was still in situ within the follow-up interval. In an average follow-up interval of 14.8 months, we were able to record an overall success rate of $75.9 \%$, which largely corresponds to the figures from the literature. As we separately interpreted the clinical outcome from the radiological outcome, we had other success rates regarding the radiological outcome defined by PAI. In the first group (1a), 64.3\% of all roots with a preoperative $\mathrm{PAI}>2$ were treated successfully. The success rate was $62.5 \%$ in the second group (1b), 33.3\% in the third group (2a), and $18.8 \%$ in the fourth group (2b), which did not receive either a root canal revision or a retrograde root filling.

It is well-known from the literature that retrograde preparation after resection has a positive effect on the prognosis of tooth preservation $[11,21]$. In our patient population, we have therefore compared retrograde prepared teeth with 
teeth that have not been prepared in a retrograde fashion. We achieved a $16.4 \%$ higher clinical success rate and a $14.5 \%$ higher radiological success rate. These results correlate with other studies, which recorded a $31 \%$ higher success rate $[21,22]$, although the evidence in this aspect must be critically assessed $[4,23]$ Regarding the retrograde filling material, a number of studies have already shown that MTA is superior to Super-EBA in terms of sealing capacity in particular, apart from the poor process ability (especially due to incorrect mixing) [2,5,7,2427]. On the other hand, we were able to record a significant difference between Super EBA and MTA, which must be viewed critically; however, the applications were not comparably high (18 times Super EBA compared to 6 times MTA).

The previous revision of an unsuccessful root canal treatment prior to initiation of surgical therapy has already been investigated in several studies. Wang et al. described a $10 \%$ higher healing chance for resected teeth which were previously orthograde revised [28]. A further study gave a $91 \%$ healing rate with at least one previously performed revision [29]. This number corresponds to our results for the groups, which were previously revised, and a clinically higher success rate of $15.2 \%$ resulted. Radiologically, this was 31\% (without retrograde root canal treatment) or $43.7 \%$ (with retrograde root canal preparation). The success rate can be further increased if the orthograde revision is performed once during root tip resection. Even if the revision entails the risk of an iatrogenic root fracture (broader preparation), it should be considered as a pre-surgical concept [10].

The tooth position is also known to influence the outcome of tooth preservation after root tip resection. In contrast to maxillary and mandibular anterior teeth, mandibular molars perform worse [30]. On the other hand, other authors showed no significant difference [31]. In our patients, the anterior teeth and molars performed significantly better than the premolars, exhibiting a success rate of $80 \%$. This finding was independent of the type of therapy and the jaw. Premolars are usually underestimated in the root anatomy. More than one-third of the mandibular premolars have more than one root canal [13]. As a result, the initial root canal treatment is usually doomed to failure and can also complicate subsequent surgical intervention. Thus, the factor of tooth position or tooth form also plays a role in the decision for a previous revision or immediate root tip resection.

within the limits of the study design, we were able to demonstrate that prior revision in persistent apical processes and retrograde preparation in surgical root tip resection should be considered to maximize treatment success. Due to the low evidence from the literature, prospective studies are needed to facilitate treatment decisions.

\section{Acknowledgements}

The present work was performed in fulfillment of the requirements for obtaining the degree Dr.med. dent. for Thomas Sottong after the state examination in dentistry at the Friedrich- Alexander- University Erlangen- Nürnberg in 2018. 


\section{References}

1) Allard U, Stromberg $T$ (1979) Inflammatory reaction in the apical area of pulpectomized and sterile root canals in dogs. Oral surgery, oral medicine, and oral pathology 48: 463-466.

2) Amezcua O, Gonzalez AC, Borges AH, Bandeca MC, et al. (2015) Sealing ability of root-end filling materials. The journal of contemporary dental practice16:210-214.

3) Amler MH (1969) The time sequence of tissue regeneration in human extraction wounds. Oral surgery, oral medicine, and oral pathology 27:309-318.

4) Ayup H, Duane B (2018) Limited evidence on best material for retrograde root fillings. Evidence- based dentistry 19: 8-9.

5) Baek SH, Lee WC, Setzer FC, Kim S (2010) Periapical bone regeneration after endodontic microsurgery with three different root-end filling materials: amalgam, SuperEBA, and mineral trioxide aggregate. Journal of endodontics 36:1323-1325.

6) Beck-Broichsitter BE, Schmid H, Busch HP, Wiltfang J, Becker ST (2018) Long-term survival of teeth in the posterior region after apical surgery. Journal of cranio-maxillo-facial surgery: official publication of the European Association for Cranio-Maxillo-Facial Surgery 46:1934-1938.

7) Benz K, Markovic L, Jordan RA, Novacek C, Jackowski J (2017) In vitro evaluation of theapical seal of two different retrograde filling materials. Australian endodontic journal: the journal of the Australian Society of Endodontology Inc 43:29-33.

8) Bernabe PF, Holland R, Morandi R, de Souza V, Nery MJ, OtoboniFilho JA, et al. (2005) Comparative study of MTA and other materials in retrofilling of pulpless dogs' teeth. Brazilian dental journal 16:149-155.

9) Torabinejad M, Lozada J, Puterman I, White SN (2008) Endodontic therapy or single toothimplant? A systematic review. Journal of the California Dental Association 36:429-437.

10) Chan CP, Lin CP, Tseng SC, Jeng JH (1999) Vertical root fracture in endodontically versus non endodontically treated teeth: a survey of 315 cases in Chinese patients. Oral surgery, oral medicine, oral pathology, oral radiology, and endodontics 87: 504-507.

11) Christiansen R, Kirkevang LL, Horsted-Bindslev P, Wenzel A (2009) Randomized clinical trial of root-end resection followed by root-end filling with mineral trioxide aggregate or smoothing of the orthograde gutta-percha root filling--1-year follow-up. International endodontic journal 42: 105-114.

12) Del Fabbro M, Corbella $S$, Sequeira-Byron P, Tsesis I, Rosen E, Lolato A, et al. (2016) Endodontic procedures for retreatment of periapical lesions. The Cochrane database of systematic reviews 10: CD005511.
13) Dou L, Li D, Xu T, Tang Y, Yang D (2017) Root anatomy and canal morphology of mandibularfirst premolars in a Chinese population. Scientific reports 7: 750.

14) Orstavik D, Kerekes K, Eriksen HM (1986) The periapical index: a scoring system for radiographic assessment of apical periodontitis. Endodontics \& dental traumatology 2: 20-34.

15) Orstavik D, Qvist V, Stoltze K (2004) A multivariate analysis of the outcome of endodontic treatment. European journal of oral sciences 112: 224-30.

16) Friedman S (2011) Outcome of endodontic surgery: a metaanalysis of the literature-part 1: comparison of traditional rootend surgery and endodontic microsurgery. Journal of endodontics 37: 577-578.

17) Friedman S (1997) Success and failure of initial endodontic therapy. Ontario dentist 74:35-38.

18) Sutherland SE (2001) Evidence-based dentistry: Part IV. Research design and levels of evidence.Journal 67:375-378.

19) Rud J, Andreasen JO, Jensen JE (1972) Radiographic criteria for the assessment of healingafter endodontic surgery. International journal of oral surgery 1:195-214.

20) Molven O, Halse A, Grung B (1987) Observer strategy and the radiographic classification of healing after endodontic surgery. International journal of oral and maxillofacial surgery $16: 432-439$

21) Kruse C, Spin-Neto R, Christiansen R, Wenzel A, Kirkevang LL (2016) Periapical Bone Healing after Apicectomy with and without Retrograde Root Filling with Mineral Trioxide Aggregate: A 6- year Follow-up of a Randomized Controlled Trial. Journal of endodontics. 42:533-537.

22) Fuss Z, Lustig J, Tamse A (1999) Prevalence of vertical root fractures in extracted endodontically treated teeth. International endodontic journal 32: 283-286.

23) Ma X, Li C, Jia L, Wang Y, Liu W, Zhou X, et al. (2016) Materials for retrograde filling in rootcanal therapy. The Cochrane database of systematic reviews 12: CD005517.

24) Schultz CB, Westhauser P, Niderost B, Klaus WG (2005) [Retrograde obturation with MTACement and Super-EBA after apicoectomy. Sealing ability of MTA and Super-EBA in dye penetration tests]. Schweizer Monatsschrift fur Zahnmedizin = Revue mensuellesuissed'odonto-stomatologie $=$ Rivistamensilesvizzera di odontologia e stomatologia 115: 442-54.

25) Song M, Kim E (2012) A prospective randomized controlled study of mineral trioxide aggregate and super ethoxy-benzoic acid as root-end filling materials in endodontic microsurgery. Journal of endodontics 38: 875-879.

26) Walivaara DA, Abrahamsson $P$, Fogelin M, Isaksson $S$ (2011) Super-EBA and IRM as root-end fillings in periapical surgery 
with ultrasonic preparation: a prospective randomized clinical study of 206 consecutive teeth. Oral surgery, oral medicine, oral pathology, oral radiology, andendodontics 112:258-263.

27) Walivaara DA, Abrahamsson P, Isaksson S, Salata LA, Sennerby L, Dahlin C (2012) Periapical tissue response after use of intermediate restorative material, gutta-percha, reinforced zinc oxide cement, and mineral trioxide aggregate as retrograde rootend filling materials: a histologic study in dogs. Journal of oral and maxillofacial surgery : official journal of the American Association of Oral and Maxillofacial Surgeons. 70: 2041-2047.

28) Wang N, Knight K, Dao T, Friedman S (2004) Treatment outcome in endodontics-The Toronto Study. Phases I and II: apical surgery. Journal of endodontics 30:751-761.

29) Zuolo ML, Ferreira MO, Gutmann JL (2000) Prognosis in periradicular surgery: a clinical prospective study. International endodontic journal 33: 91-98.

30) vonArx T, Penarrocha M, Jensen S (2010) Prognostic factors in apical surgery with root-end filling: a meta-analysis. Journal of endodontics 36: 957-973.

31) Taschieri S, Machtou P, Rosano G, Weinstein T, Del Fabbro M (2010) The influence of previous non-surgical re-treatment on the outcome of endodontic surgery. Minerva stomatologica 59: 625-632.

\footnotetext{
Submit your manuscript to a JScholar journal and benefit from:

๑ Convenient online submission

ฯ Rigorous peer review

I Immediate publication on acceptance

ๆ Open access: articles freely available online

๑ High visibility within the field

- Better discount for your subsequent articles

Submit your manuscript at http://www.jscholaronline.org/submit-manuscript.php
} 